\title{
Politizando o conceito de redes organizacionais: uma reflexão teórica da governança como jogo de poder
}

\author{
Beatriz Christo Gobbi * \\ Elcemir Paço Cunha** \\ Mozar José de Brito*k* \\ Igor Senger *wok
}

\section{Resumo}

Este trabalho tem como objetivo apresentar uma reflexão teórica sobre a dimensão política das redes organizacionais. Para tanto, procurou fazer uma análise desse formato organizacional, privilegiando a dimensão política das relações interorganizacionais a partir de alguns conceitos formulados pelo sociólogo Pierre Bourdieu. As evidências teóricas revelaram que esse recorte analítico poderá oferecer leituras alternativas às reflexões que despolitizam o conceito de redes organizacionais, colocando no epicentro das argumentações a lógica da cooperação e da confiança como forças motrizes e suficientes para explicar o funcionamento das relações entre as organizações. Ao considerar as redes organizacionais como um campo social, este ensaio amplia a noção de governança, levando em consideração não só os aspectos estruturais e objetivos, mas também a dimensão subjetiva que permeia as relações entre os agentes.

Palavras-chave.: redes organizacionais; governança em rede; Bourdieu.

\begin{abstract}
This paper presents a theoretical reflection on the political dimension of the networks. It tried to analyze this format organization, privileging the political dimension of the relationships inter-organizational based on some concepts formulated by sociologist Pierre Bourdieu. The theoretical evidences revealed that such perspective can offer an alternative understanding to the concepts which don't put the idea about networks in political terms, considering cooperation and trust as driving forces which explains entirely the connections among the organizations. Considering the networks as a social field, this article enlarges the idea on governance. It takes into consideration not only the structural and objective aspects, but also emphasizes the subjective dimension that permeates the relations among the agents.
\end{abstract}

Keywords.: networks; network governance; Bourdieu.

\section{Introdução}

A emergência e a proliferação de novas formas organizacionais vêm assumindo um papel de destaque no mundo dos negócios. Na literatura especializada, esses novos arranjos passaram a ser considerados como uma forma híbrida de governança, ampliando a dicotomia de mercado baseada na racionalidade das transações e na hierarquia, na qual a coordenação se baseia no poder formal delegado aos agentes.

A partir das contribuições da concepção de imbricamento (embeddness,) destacou-se a ação econômica dos agentes e das instituições, passando a vinculá-la ao emaranhado das redes de relações nas quais estão inseridas. Com isso, percebeu-se a necessidade de diferentes lógicas de coordenação do trabalho, baseadas na racionalidade de cada troca, na regulação, no poder formal, além dos mecanismos sociais.

\footnotetext{
*Professora UNIPAC/RAUL. Mestre em administração UFLA. E-mail:beatrizlavras@ ufla.br.

** Professor UFJF. Mestre em administração UFLA. E-mail: epcadm@ hotmail.com.

*** Professor ULFA. Doutor em Admnistração pela USP. E-mail: mozarjdb@ ufla.br.

**** Professor UNICEN/Primavera do Leste. Mestre em administração UFLA. E-mail: isenger@ ufla.br.

Artigo recebido em julho de 2004 e aprovado em setembro de 2004.
} 
Entretanto, a variedade de formas, de tamanho e natureza das redes e a conseqüente complexidade das relações propiciaram uma leitura fragmentada do fenômeno. As abordagens sobre as redes geralmente apresentam ausência de fundamentação teórica e de conceitos claros. Além disso, freqüentemente, estabelecem um foco estático, negligenciando a dinâmica política do processo, enfatizando a estrutura em detrimento de padrões de evolução.

De modo geral, a governança das redes vem sendo tratada como uma estrutura e/ou processo que visa ao ajustamento da ação entre entidades autônomas, para o estabelecimento de uma ordem que garanta que o comportamento individual das unidades seguirá as regras para a ação coletiva.

Essas abordagens privilegiam o controle a partir da percepção da mútua dependência, do desenvolvimento da cooperação e do estabelecimento da confiança entre as partes. Entretanto, o estabelecimento da cooperação nem sempre é harmonioso e fácil. O conflito pode chegar mesmo com a dependência entre as partes, podendo ocorrer tensão entre essa dependência e a diversidade de objetivos e interesses. O estabelecimento do "jogo político" não é tanto um esforço acadêmico quanto pode ser uma capitulação aos aspectos conflituosos das relações no espaço social.

Este trabalho tem como objetivo apresentar uma reflexão sobre a dimensão política das redes organizacionais. Para tanto, busca oferecer uma leitura das redes que privilegia a dimensão política das relações interorganizacionais, a partir de algumas contribuições da sociologia de Pierre Bourdieu. O entendimento das redes como um campo social pode ampliar as perspectivas de análise ao considerar a realidade como uma construção social, consolidada a partir da gênese social da cumplicidade ontológica entre os esquemas de percepção dos agentes e as estruturas objetivas.

Nessa direção, a rede organizacional é um espaço plural onde coexistem diferentes agentes com diferentes capitais e interesses; o que pode incorrer em situações de conflitos e disputas, em detrimento do consenso e da harmonia que predominam nas investigações nesse campo organizacional.

Assim como outros conceitos da sociologia de Bourdieu, a noção de campos de poder pode ser útil para o entendimento da lógica existente nas práticas dos agentes sociais em um espaço social desigual e conflituoso marcado por disputas políticas nem sempre explícitas - e para a compreensão de como os mecanismos de governança podem emergir a partir dessa complexidade. Essa discussão será apresentada neste artigo, em três partes seguidas das considerações finais. A primeira parte analisa a governança em redes como processo de coordenação das interações interorganizacionais. Na segunda parte são abordadas as proposições analíticas da sociologia de Pierre Bourdieu, destacando-se o seu potencial analítico para o campo dos estudos. A última parte apresenta uma análise das redes organizacionais, a partir da perspectiva de Bourdieu, considerando assim a dimensão política e a lógica do poder no processo de constituição e funcionamento das organizações em rede.

\section{Governança em rede e a lógica das relações interorganizacionais}

A concepção de "rede" vem sendo amplamente utilizada para analisar os arranjos organizacionais e intraorganizacionais. Internamente, o sentido da hierarquia e as fronteiras que delimitavam a burocracia estão se reconfigurando, buscando maior capacidade de resposta ao ambiente e formas alternativas de coordenação e controle. Externamente, as fronteiras que delimitavam as organizações estão diminuindo à medida que as entidades se fundem e/ou se articulam de forma conjunta, caracterizando assim o que alguns autores chamam de organizações pós-fordistas (CLEGG e HARDY, 1999).

Esses autores argumentam que o pressuposto básico é o da articulação conjunta entre as organizações, visando à diluição de riscos e ao compartilhamento de recursos, evitando a duplicação onerosa de esforços individuais, obtendo maior acesso ao know-how e às informações, por meio de relações de colaboração com relações mais flexíveis. 
Assim, os termos "rede de empresas", "organizações em rede", "alianças estratégicas", "redes organizacionais", "network" ou "quase-empresas", entre outros tantos usados para designar essas novas formas organizacionais, freqüentemente referem-se à coordenação que se estabelece entre as várias organizações do arranjo (PECI, 2000).

$\mathrm{Na}$ literatura especializada, a partir das contribuições da sociologia econômica de Granovertter (1985), as redes são vistas como uma forma híbrida de governança (POWELL, 1990), ampliando a dicotomia entre o mercado, baseado na racionalidade das transações, e a hierarquia, na qual a coordenação baseia-se no poder formal delegado aos agentes (WILLIAMSON, 1975). Essa ampliação implica, assim, diferentes lógicas de coordenação do trabalho entre as organizações, baseadas na racionalidade de cada troca, no estabelecimento de regras e no poder formal, além dos mecanismos sociais (PECI, 2000).

Para Granovertter (1985), o comportamento econômico está imbricado (embedded) em contextos sociais particulares que moldam o comportamento dos atores em decorrência dessas interações. Powell (1990) corrobora essas idéias quando argumenta que existe uma grande variedade de situações que dão origem aos arranjos em rede. Para esse autor, a redução dos custos de transação não é a única causa da emergência das redes organizacionais. Portanto, pode-se afirmar que as redes emergem em contextos particulares, com sua própria historicidade, com estruturas que constrangem as ações e também são constrangidas por estas.

Em função disso, a ação, as atitudes e o comportamento dos atores nas organizações podem ser melhor explicados em termos de sua posição na rede de relacionamento. Em outras palavras, as redes são construções sociais reproduzidas e alteradas como resultado da ação dos atores que as constituem (POWELL, 1990).

A partir da análise de padrões de relações estabelecidos entre diferentes atores imbricados em contextos particulares é possível transcender a visão atomizada dos homens, não se limitando a uma perspectiva subsocializada, baseada no pensamento econômico da ação racional e utilitária na busca do auto-interesse, e na visão sobre-socializada, que limita a ação às regras, normas e valores instituídos (ANDRADE, 2003). O comportamento econômico tem também outros objetivos além do econômico, como a sociabilidade, a aprovação, o status e o poder (GRANOVERTTER, 1992).

A inseparabilidade entre indivíduo e estrutura leva à conclusão de que a lógica de funcionamento dessas novas formas organizacionais, calcadas na mútua dependência, acarreta relacionamentos de complementaridade e reciprocidade (POWELL, 1990; NOHRIA, 1992; CASTELLS, 1999) e gera contradições inerentes (KLIJN e KOPPENJAN, 2000). Ao mesmo tempo em que a concepção de "rede" incentiva fortemente a coordenação de mercado, assume a estabilidade da hierarquia como fator de coordenação. Essas contradições também são verdadeiras quando da imposição da necessidade de cooperação e do aparecimento de competição e riscos entre as partes envolvidas na rede. Em síntese, concomitantemente à autonomia, emerge a mútua dependência (KLIJN e KOPPENJAN, 2000).

Além disso, a variedade de formas desses novos arranjos organizacionais, o tamanho e a natureza das relações - que passam a apresentar vários modos de interação, envolvendo inúmeros atores detentores de diferentes recursos e interesses - interferem no processo de controle entre os agentes (CHILD e RODRIGUES, 2002). Nesse contexto, a alocação dos direitos de decisão apresenta o desafio de "conciliar" decisões coletivas com ações individuais (SAUVÉE, 2003).

Apesar do interesse despertado nos últimos 20 anos, a diversidade de contextos, e a própria complexidade das relações com o conceito de rede, gerou uma literatura fragmentada sobre as relações interorganizacionais. Essa fragmentação incorre na ausência de fundamentação teórica e de conceitos claros (KLIJN e KOPPENJAN, 2000; ALVAREZ e SVEJENOVA, 2003; JONES, HESTERLY e BORGATTI, 1997) e frequientemente estabelece um foco estático, negligenciando a dinâmica do processo, ao dar maior ênfase às estruturas do que aos padrões de evolução (BENASSI, 1995). 
Essa perspectiva estrutural - na qual se procura determinar novas formas de governança e controle a partir de relações de cooperação e confiança - relega a um segundo plano os aspectos relacionais e processuais (ANDRADE, 2003), negligenciando as relações de poder (KLIJN e KOPPENJAN, 2000). Ela não é clara sobre o que é a "governança" de organizações em rede e como ela pode ocorrer. Geralmente, as definições sobre a coordenação das relações limitam-se a dois conceitos: o de modelo de interação e dos relacionamentos e o de fluxos de recursos entre as partes independentes (JONES, HESTERLY e BORGATTI, 1997). De forma geral, a governança em rede vem sendo abordada como uma estrutura e/ou processo cujo propósito é regular a ação coletiva articulada entre entidades autônomas, de modo a criar uma ordem negociada que garanta que o comportamento individual das unidades será orientado pelas regras estabelecidas para a ação coletiva.

Algumas perspectivas sobre a governança nas organizações em rede podem ser elucidadas, nas quais sobressai o tratamento residual dos aspectos conflituosos. Para Jones, Hesterly e Borgatti (1997), por exemplo, a governança nas redes visa assegurar e salvaguardar as trocas. Os autores integram a teoria de custo de transação com a teoria de redes sociais para entender como o processo de governança emerge e prospera nas redes. Nesse sentido, a forma de governança pode ser vista como a resposta das redes organizacionais às condições de troca em ambiente de alta complexidade marcado pela especificidade dos ativos humanos, pela complexidade das tarefas, pela incerteza de demanda e pela freqüência com que as trocas se realizam. Os mecanismos sociais como a restrição de acesso, a macrocultura, as sanções coletivas e a reputação - são capazes de assegurar e salvaguardar as trocas, funcionando como mecanismos de coordenação.

Para os autores, a governança corporativa em rede se refere a um conjunto selecionado, persistente e estruturado de empresas autônomas, que se envolvem na criação de produtos ou serviços baseados em contratos implícitos, freqüentemente abertos para que elas possam adaptar-se às contingências ambientais e, assim, coordenar e salvaguardar os termos de intercâmbio estabelecidos (JONES, HESTERLY e BORGATTI, 1997).

Outra abordagem, com base nas idéias de Granovertter (1985; 1992), procura compreender como os arranjos e as interações se dão a partir do imbricamento social. Gulati (1999) considera que propriedades relacionais, estruturais e posicionais interferem no processo de desenvolvimento da confiança e da cooperação entre as partes envolvidas. O processo de interação entre os atores é afetado pela estrutura de relações, pela posição organizacional na estrutura, além dos fatores ligados à interdependência entre as partes, considerando seu impacto na predisposição à cooperação.

Benassi (1995) defende que a governança é um processo dinâmico, afetado por dois fatores distintos e, ao mesmo tempo, entrelaçados. O primeiro é a teoria de rede apreendida pela empresa focal, ou seja, o repertório cognitivo organizacional em relação ao processo de ação coletiva e em relação à compreensão da arquitetura organizacional. O outro fator, decorrente do primeiro, consiste no modo de controle usado pela organização. Segundo o autor, esses dois fatores influenciam na tendência das organizações de cooperarem entre si e nos possíveis resultados relacionados ao processo de cooperação.

Alvarez e Svejenova (2003), ao estudarem de uma perspectiva macrossocial a evolução da governança em rede, constataram o impacto das diferenças de identidade dos agentes nas dimensões desse processo de governo. Em outros termos, as diferenças das identidades desses agentes conduzem às diferenças de estratégias para a composição das redes e a articulação entre as entidades.

A distribuição de direitos de decisão na rede - de forma unificada, ao redor de propósitos estratégicos - e o desenvolvimento de mecanismos interorganizacionais por meio de sistemas de incentivos e de controle também podem ser entendidos como meios de se chegar ao estabelecimento de mecanismos de governança (SAUVÉE, 2002, 2003).

Em sua análise de redes de telefonia, Ende (2003) destaca o papel preponderante que o ciclo de vida do produto tem na definição do modo de governança. Essa análise se refere ao grau de incerteza e urgência envolvido nas transações. Assim, o modo de governança é fator de maturidade das redes e de maturidade dos serviços. 
A percepção da interdependência entre as organizações também motiva os atores a desenvolverem estruturas de coordenação. Essas estruturas de coordenação são decorrentes da metaestrutura, mesoestrutura e microestrutura (ALEXANDER, 1996). A metaestrutura é o nível social envolvendo o campo organizacional por inteiro, definindo as características básicas da interação interorganizacional em seus campos. No âmbito intraorganizacional, ou seja, na mesoestrutura, é o espaço no qual se dá o desenvolvimento de redes informais e a conseqüente apreensão da dependência. O autor sugere que o nível mais baixo envolve a microestrutura, que são os dispositivos para ligar centros de decisão intra ou interorganizacionais.

Outra concepção, que envolve o estabelecimento de percepção da necessidade de cooperar, consiste no que Calton e Lad (1995) chamam de contratos relacionais. Segundo esses autores, esses contratos envolvem valores compartilhados, sendo ordenados nos padrões de interação, envolvendo a expressão do processo de contrato microssocial gradualmente imbricado, moldado pela cultura que define a ordem negociada. Dessa forma, os autores denotam que o contrato microssocial é o processo pelo qual os participantes da rede definem a si mesmos e o significado de seu empreendimento, por meio de padrões interativos, estabelecendo significados, critérios e regras que governam os esforços comuns.

Em um estudo desenvolvido em sistemas produtivos locais, Suzigan, Garcia e Furtado (2002) constataram que, além dos mecanismos do mercado, o tipo de governança varia conforme o tipo de sistema produtivo local, determinado por sua estrutura de produção, pela aglomeração territorial, pela organização industrial, pela inserção no mercado (interno e externo), pela densidade institucional (atores coletivos, privados e públicos) e pelo tecido social.

A partir dessas abordagens, percebe-se que, de modo geral, a literatura de governança vem utilizando a percepção da dependência entre as partes, o desenvolvimento da cooperação e o estabelecimento da confiança como mecanismos para assegurar a ação coletiva. Embora utilizem a concepção de imbricamento social, ou seja, que as ações econômicas não acontecem no vácuo, as teorias não consideram as possíveis assimetrias, tratando de forma residual as relações entre os agentes inseridos na rede.

Klijn e Koppenjan (2000) alertam para o fato de que o estabelecimento da cooperação nem sempre é harmonioso e fácil. Mesmo com a dependência entre as partes, o conflito pode chegar, por exemplo, ao processo de distribuição de custos e benefícios das ações conjuntas. Pode ocorrer ainda tensão entre a dependência e a diversidade de objetivos e interesses. O estabelecimento de regras nem sempre resolve as tensões decorrentes, sendo necessário o estabelecimento do "jogo político".

A partir da abordagem de governança como um processo político, Klijn e Koppenjan (2000) e Borzel, (1998) argumentam que a interação entre os atores acontece focalizando a resolução da tensão entre as dependências, por um lado, e a divergência de interesses, por outro; tensão na qual os atores percebem a arena política e selecionam estratégias específicas. Essa abordagem considera o processo de coordenação complexo devido à variedade de agentes, percepções e estratégias. Assim, para os autores, as relações políticas são o resultado das complexas interações entre os atores participantes, instituindo o "jogo" dentro de uma rede de atores.

Partindo do pressuposto que as redes organizacionais são coletividades que incorporam uma dimensão política, julga-se que as formulações de Bourdieu (1996, 1998, 2000 e 2003) podem ampliar o potencial analítico da teoria das organizações, bem como trazer novas contribuições para o entendimento da problemática das relações interorganizacionais. As interações entre organizações em rede podem ser entendidas como um campo de relacionamento entre os agentes sociais - variando de acordo com as características objetivas de sua constituição como campo - e as diversas representações produzidas pelos agentes da rede interorganizacional, assim como nas análises do campo econômico, campo científico, campo artístico e campo burocrático empreendidas pelo autor.

Acredita-se que a noção de campo social e outros conceitos formulados por Bourdieu podem ser empregados na compreensão da lógica das práticas dos agentes em um espaço social desigual (em que os agentes não são indiferentes às posições ocupadas por outros agentes) e como os mecanismos de governança podem emergir a partir dessa complexidade. 


\section{Proposições analíticas da teoria do campo social}

Ao formular a teoria do campo social, Pierre Bourdieu recorreu aos postulados do estruturalismo crítico e da visão construtivista. O objetivo era procurar demonstrar que a análise das estruturas objetivas é inseparável da análise de sua gênese, dos agentes participantes e de suas estruturas mentais, que são em parte produto da incorporação das estruturas sociais e da análise da gênese, que por sua vez resultam em parte da incorporação das estruturas sociais e da análise da gênese destas próprias estruturas. Assim, Bourdieu (1996, 1998, 2000 e 2003) desenvolveu elementos para análise das diferentes realidades sociais, a partir de uma série de conceitos. Considerando o objetivo deste estudo, alguns desses elementos e o potencial analítico serão objeto da sistematização teórica que se segue.

\section{Fundamentos da teoria do campo social}

Para Bourdieu (1998), ao se analisar a realidade, deve-se tomar como referência a noção de que o mundo social pode ser entendido como um espaço de várias dimensões. Esse espaço social define o mundo social constituído de diversos campos por meio da diferenciação ou distribuição, de modo que cada campo possui suas propriedades e regras que são produto e produtoras da ação dos agentes. Esse mesmo espaço é constituído pelo "conjunto das propriedades que atuam no universo social considerado, quer dizer, apropriadas a conferir, ao detentor delas, força ou poder neste universo" (BOURDIEU, 1998, p.133 e 134).

Os diversos agentes e grupos de agentes podem ser definidos em função das suas posições relativas no espaço. Os agentes ocupam posições (e posições vizinhas), mas não podem ocupar duas regiões opostas do espaço. Além disso, na medida em que

as propriedades tidas em consideração para se construir este espaço são propriedades atuantes, ele pode ser descrito também como campo de forças, quer dizer, como um conjunto de relações de forças objetivas impostas a todos os que entrem nesse campo e irredutíveis às interações dos agentes individuais ou mesmo às interações diretas entre os agentes (BOURDIEU, 1998, p.133).

O que constitui o espaço social mais amplo são os múltiplos campos (ou regiões específicas do espaço), com a desigual distribuição dos diferentes tipos de capitais. De modo geral, esses capitais são representados pelo capital econômico (os fatores de produção e o conjunto de bens econômicos), pelo capital cultural (o conjunto de qualificações intelectuais), pelo capital social (conjunto de relações sociais de que dispõe um determinado indivíduo ou grupo) e pelo capital simbólico (qualquer um desses capitais, seja o econômico, o social ou o cultural), que é reconhecido por sua capacidade de exercer poder, não no plano da força física, mas no plano do valor que os demais agentes atribuem a um tipo de capital. $\mathrm{O}$ capital simbólico possui a propriedade de ser convertido em outros tipos de capital e, geralmente, pode ser entendido como reputação (BOURDIEU, 1998).

Com efeito, o capital pode existir no estado objetivado, em forma de propriedades materiais, ou ainda, como no caso do capital cultural, no estado incorporado. Esse estado incorporado é juridicamente garantido, representando poder sobre o campo em determinado momento, ou mais precisamente sobre o produto acumulado do trabalho passado. As espécies de capital funcionam, assim, como trunfos no jogo, exercendo poder e definindo as propriedades do campo e as probabilidades de ganho dos agentes envolvidos (BOURDIEU, 1998).

Dessa forma, essas noções de capitais ampliam a perspectiva de análise das ações dos agentes, que nem sempre estão voltadas para a maximização racional de seus interesses, como explica Bourdieu, pela lógica da economia dos campos:

A teoria geral da economia dos campos permite descrever e definir a forma específica de que se revestem, em cada campo, os mecanismos e conceitos mais gerais (capital, investimento, ganho), 
evitando assim toda espécie de reducionismo, a começar pelo economismo, que nada mais reconhece além do interesse material e a maximização do lucro monetário (BOURDIEU, 1998, p.69).

A posição dos agentes no espaço social depende do volume e da estrutura do seu capital. Os agentes detentores de capitais determinantes em dado campo tentam se impor a todos, legitimando a sua visão de mundo, num princípio de movimento constante, a partir das lutas produzidas pela própria estrutura constitutiva do campo.

Os agentes distribuem-se assim neles, na primeira dimensão, segundo o volume global de capital que possuem e, na segunda dimensão, segundo a composição de seu capital - quer dizer, segundo a composição e o peso relativo das diferentes espécies no conjunto de suas posses (BOURDIEU, 1998, p.135).

Essa concepção chama a atenção para as diferentes atribuições de valor e a conseqüente legitimação dos vários tipos de capital nos diversos campos. Ou seja, em dado campo, a posse de determinado tipo de capital terá uma maior relevância e, conseqüentemente, um maior impacto, podendo constituir-se como geradora de poder, diferentemente de outros campos. Essa propriedade atribui ao estado das relações de força - institucionalizado em estatutos sociais duradouros, socialmente reconhecidos ou juridicamente garantidos entre agentes objetivamente definidos por suas posições - as diferenças entre diferentes agentes (BOURDIEU, 1998). Em outras palavras, a distribuição das diferentes espécies de capital garante a estrutura das relações de poder entre os agentes.

Em termos analíticos, um campo pode ser definido como uma rede ou uma configuração de relações objetivas entre posições. Essas posições são definidas objetivamente em sua existência e nas determinações que elas impõem aos seus ocupantes, agentes ou instituições, por sua situação (situs) atual e potencial na estrutura da distribuição das diferentes espécies de poder (ou de capital), cuja posse comanda o acesso aos lucros específicos em questão e, ao mesmo tempo, por suas relações objetivas com as outras posições (dominação, subordinação, homologia etc) (BOURDIEU e WACQUANT, apud BONNEWITZ, 2003, p.60).

Ainda na direção das relações de força, a noção de espaço e campo contém o princípio de uma apreensão relacional do mundo social, a partir da idéia de que toda a realidade reside na exterioridade mútua dos elementos que a compõem. Os seres sociais, sejam individuais ou coletivos, existem e subsistem nas e pelas diferenças, entendidas como as posições relativas em um espaço de relações, ainda que não seja visível e mesmo difícil de expressar esse jogo (BOURDIEU, 1996).

O campo é, então, um espaço de diferentes e de diferenças. A tomada de posições nos campos se dá pela intermediação das disposições incorporadas, o que o autor chama de habitus. Por sua vez, o habitus funciona como o princípio gerador e unificador que "retraduz" as suas características intrínsecas e relacionais das posições nos determinados campos. Dessa forma, ao mesmo tempo em que são produtos das posições, os habitus são diferenciados, mas também diferenciadores (BOURDIEU,1996).

O habitus funciona então como uma matriz de percepções, apreciações e ações, que torna possível a realização de tarefas infinitamente diferenciadas. Ele tende, ao mesmo tempo, a reproduzir as regularidades inscritas nas condições objetivas e estruturais, mas permite o ajustamento e inovações quanto às exigências expostas pelas situações concretas que põem à prova a sua eficiência. O habitus é assim entendido como um sistema de disposições adquiridas por meio da socialização; são estruturas estruturadas dispostas a funcionar como estruturas estruturantes (BOURDIEU, 1996).

(...) sistemas de disposição duradouros e transponíveis, estruturas estruturadas dispostas a funcionar como estruturas estruturantes, isto é, como princípios geradores e organizadores de práticas e representações que podem ser objetivamente adaptadas ao seu objetivo, sem supor a visada consciente de fins e o controle expresso das operações necessárias para atingi-los, objetivamente reguladas e regulares, 
sem ser em nada o produto da obediência a regras, e sendo tudo isso, coletivamente orquestradas, sem ser o produto da ação organizadora de um maestro" (BOURDIEU, apud BONNEWITZ, 2003, p.7677).

Logo, o habitus completa o movimento de interiorização das estruturas exteriores, pois as práticas dos agentes exteriorizam esses sistemas de disposições incorporados. Ele é o modus operandis e condição primeira de qualquer objetivação, exigindo de parte dos grupos e/ou das classes, um mínimo de controle e domínio de um código comum (BOURDIEU, 2003). Constitui, ainda, o princípio gerador e unificador do conjunto de práticas e das ideologias características de um grupo de agentes.

A relação entre o habitus e o campo é antes de tudo uma relação de condicionamento: o campo estrutura o habitus, que é produto da incorporação da necessidade imanente desse campo ou de um conjunto de campos mais ou menos concordantes - as discordâncias podem estar no princípio do habitus divididos, ou até dilacerados. Mas também é uma relação de conhecimento ou de construção cognitiva: o habitus contribui para construir o campo como mundo significante, dotado de sentido e de valor, no qual vale a pena investir energia (BOURDIEU e WACQUANT, apud BONNEWITZ, 2003, p.85).

Assim, as ações coletivas de um grupo aparecem como produto dessas disposições e de um acontecimento objetivo, uma vez que a tomada de consciência requer um determinado tipo de disposição e a posse direta ou imediata de um discurso capaz de assegurar o domínio simbólico dos princípios dominados pelo habitus de determinado grupo (BOURDIEU, 2003). Então, o poder simbólico acumulado em dado campo consiste na autoridade, condição de legitimidade que permite agir dentro do campo (BOURDIEU, 1998). Contudo, cabe ressaltar que o campo não é uma estrutura estática; ele apresenta-se em constante movimento, gerado pelas lutas produzidas pelas próprias estruturas constitutivas do campo, as quais reproduzem as suas estruturas e as hierarquias, gerando uma tensão entre as posições (BOURDIEU, 1998). Desse modo, os agentes em posição de vantagem irão desenvolver estratégias individuais e coletivas, objetivando conservar ou acumular o máximo de capitais possíveis, dentro da estrutura de funcionamento. Por outro lado, os agentes em condições desfavoráveis poderão procurar transformar as regras do campo, constituindo assim um campo de poder e de luta pela acumulação de capital.

Contudo, o espaço social também é um espaço de luta pelo domínio do Estado (BOURDIEU, 1996). De modo geral, o Estado, fazendo uso da violência física e simbólica, possui meios de instaurar e inculcar "formas e categorias de percepção e de pensamento comuns, quadros sociais da percepção, da compreensão ou da memória, estruturas mentais, formas estatais de classificação" (BOURDIEU, 1996, p.116). Criam-se assim formas de interpretação da realidade compartilhadas em determinado território e, por conseguinte, institucionalizam-se as bases para a obtenção de legitimidade de determinadas "práticas".

O Estado é, em si, um banco de capital simbólico, como prefere Bourdieu, na medida em que ele "contribui de maneira determinante na produção e reprodução dos instrumentos de construção da realidade social" (BOURDIEU, 1996, p.116), concentrando e exercendo poder simbólico. Nesse sentido, o Estado não tem necessariamente que dar ordens, que exercer coerção física para produzir uma ordenação do mundo social, enquanto, pelo menos, puder produzir estruturas cognitivas incorporadas que estejam em consonância com as estruturas objetivas, garantindo assim a submissão legítima à ordem estabelecida.

O Estado é o detentor de um tipo de capital entendido como "metacapital", com poder sobre os diferentes tipos de capitais e sobre os seus detentores. A construção do Estado é equivalente à construção do campo de poder,

entendido como o espaço de jogo no interior do qual os detentores de capital (de diferentes tipos) lutam particularmente pelo poder sobre o Estado, isto é, sobre o capital estatal que assegura o poder sobre os diferentes tipos de capital e sobre sua reprodução (BOURDIEU, 2003, p.99-100). 
Bourdieu explica que o campo de poder não deve ser confundido com o campo político. O campo de poder não é um campo como os outros, mas coexiste com os outros campos. Ele é um espaço de relações de força entre os diferentes tipos de capital, entre os agentes providos com diferentes tipos e quantidades de capital, visando, por meio dos habitus adquiridos, dominar o campo correspondente e cujas lutas se intensificam sempre que o valor relativo dos diferentes tipos de capital é questionado, ou seja, quando o equilíbrio estabelecido no interior do campo é interrompido. É o que o autor considera como conservação ou transformação da "taxa de câmbio" entre os diferentes tipos de capital, ou ainda sobre as diversas instâncias que podem alterar essa relação por meio de medidas legais (BOURDIEU, 1996). O Estado ocupa importante lugar na definição dessas "taxas de câmbio", na medida em que ele detém grande poder na construção de ordens instituídas. Todavia, a dominação não é o efeito direto e simples da ação exercida por um conjunto de agentes investidos de poderes de coerção, mas efeito indireto de um conjunto complexo de ações que se engendram na rede cruzada das limitações dos dominantes e dos dominados na estrutura do campo (BOURDIEU, 1996). As diferenças associadas às posições diferentes funcionam em cada campo, como as diferenças constitutivas de sistemas simbólicos; ou seja, como um conjunto de práticas e condutas, que passa a ser aceito e reconhecido como legítimo (BOURDIEU, 1998).

Cada campo tem os seus mecanismos de funcionamento. Os agentes detentores de maior volume dos diferentes tipos de capitais, assumem a posição de dominantes, impondo ao campo o seu ponto de vista. A imposição leva à produção do que o autor chama de "doxa", a qual leva o conjunto do grupo social a aceitar aquilo que é entendido como legítimo (Bourdieu, 1996). A doxa é o ponto de vista dos dominantes que exercem seu domínio controlando o Estado (detentor de todos os detentores de diferentes tipos de capital).

Para que a universalização da visão individual, da doxa, em detrimento da visão coletiva, se concretize, ocorre a oferta, em diferentes graus, de lucros materiais e simbólicos. Para o autor, o lucro da universalização é um dos motores históricos do progresso do universal, favorecendo a criação de domínios nos quais são reconhecidos valores universais instaurados em processo de reforço circular entre as estratégias de universalização (para obter lucros, mesmo que negativos), associados à conformação às regras universais e às estruturas desses domínios oficialmente consagrados ao universal (BOURDIEU, 1996).

As estratégias de universalização fundamentam todas as normas e todas as formas oficiais. A partir de seus doxas, os campos sociais universais estabelecem as suas leis fundamentais, independentemente dos outros universos, naquilo que o autor chama de nomos (BOURDIEU, 1996). Assim, ao se instituir na objetividade de uma regra, ou de um regulamento escrito, que passou a governar as condutas no estado prático, permite que ocorra o que se chama de homologação, ou seja, os diferentes atores passam a perceber e atribuir o mesmo sentido aos códigos estabelecidos e são, por isso, legítimos (BOURDIEU, 1998).

Ainda no que se refere ao funcionamento dos campos, todos estes tendem a obter, dos que neles entram, uma relação de envolvimento e de investimento. Os agentes podem querer inverter as relações de força no campo, reconhecendo os alvos; não sendo, dessa forma, indiferentes ao funcionamento do respectivo campo. É o que o autor chama de "illusio" ou investimento nessa "relação encantada com um jogo que é produto de uma relação de cumplicidade ontológica entre as estruturas mentais e as estruturas objetivas do espaço social" (BOURDIEU, 1996, p.139-140).

Nessa direção, mesmo que se tente mudar as estruturas do campo, os agentes concordam com o essencial do que é tacitamente exigido por esse campo, considerando que ele é importante e que o que está em jogo é tão significativo a ponto de se desejar fazer nele uma revolução. Existe, ainda, entre os agentes que ocupam posições opostas e que parecem radicalmente divergentes nas suas concepções, um acordo oculto e tácito a respeito do fato de que vale a pena lutar pelos capitais que estão em jogo no campo. O illusio é, dessa forma, tanto condição quanto produto do funcionamento do campo (BOURDIEU, 1996).

Concomitante ao illusio, outra força que condiciona o funcionamento dos campos é a libido social, que são os interesses específicos socialmente constituídos, que apenas existem em relação a um espaço social, no interior 
do qual certas coisas podem ser consideradas importantes e outras são consideradas indiferentes (BOURDIEU,1996).

Apesar de sua diferenciação, cada campo não tem limites claramente definidos e nem sempre é totalmente autônomo em relação aos outros campos, podendo sofrer influência de outros campos, como, por exemplo, o campo econômico, estruturado por múltiplas organizações e instituições, ou o campo burocrático (o Estado), representado pelas instâncias reguladoras que podem, por sua vez, modificar ou fixar novas regras do jogo.

Nesse sentido, a reprodução da lógica do campo, dotado de autonomia relativa, envolve uma regionalização da realidade social, cujos fundamentos derivam tanto do processo histórico singular como das categorias aí produzidas, que passam a informar e justificar o princípio de diferenciação e as lutas que se estabelecem pela acumulação de capital global ou pelo próprio domínio do "metacapital", do poder de interferir na construção, manutenção e mudança da realidade social (BOURDIEU, 2003).

\section{Potencial analítico e teoria do campo}

Essa metodologia pode indicar as diferenças reais que separam tanto a estrutura objetiva quanto as disposições subjetivas, cujo princípio é preciso procurar não nas singularidades da natureza, mas nas particularidades das diferentes histórias coletivas (BONNEWITZ, 2003).

A noção de campo propicia algumas vantagens para a explicação da realidade social. Ela considera ao mesmo tempo os princípios de divisão interna em função dos quais se organizam os conflitos, as controvérsias, as competições e os limites historicamente determinados que o funcionamento do campo impõe (PINTO, 2000).

A abordagem dos campos de Bourdieu apresenta um aspecto relacional, atribuindo primazia às relações, sendo também considerada uma filosofia de ação posicional que atualiza as potencialidades inscritas nos corpos dos agentes e na estrutura das situações nas quais eles atuam. Essa visão tenta romper com as dualidades estanques entre objetivo/subjetivo, individual/coletivo, interessado/desinteressado, consciente/inconsciente, entre outros (BONNEWITZ, 2003).

O entendimento do campo de poder como um espaço paralelo concomitante com o campo em questão - onde se destacam as desigualdades e as lutas, sempre que o equilíbrio entre os agentes e os seus capitais é posta em questionamento - destaca as relações de disputa de poder entre os diferentes grupos que estruturam o campo (PINTO, 2000).

Dentro dessa ótica, a sociologia de Bourdieu pode ser útil na integração dos níveis de análise macro e microorganizacionais, na medida em que as proposições formuladas por esse autor considera tanto a dimensão objetiva (mais presente nas análises microorganizacionais) quanto a dimensão subjetiva da realidade (mais comum nas análises macroorganizacionais) (MISOCZKY, 2001).

No Brasil, alguns estudos já utilizaram o aparato teórico e metodológico de Bourdieu para analisar alguns campos organizacionais, mais precisamente no campo cultural. Nessas pesquisas foram analisadas a formação e a estruturação do campo organizacional dos museus e teatros nos estados de Pernambuco e Rio Grande do Sul (LEÃO, 2001 e VIEIRA, CARVALHO e LOPES, 2003).

Dessa forma, pode-se produzir uma síntese das contribuições da noção de campos de poder para a análise dos campos organizacionais realizada por Leão (2001), a partir das considerações de Misoczky (2001): foco em processos, em relações; os agentes são ativos e atuantes; a ação tem caráter intencional, mas não "estratégico"; a organização é uma construção social; gênese social dos esquemas de percepção e da estrutura; relações de poder e disputas de interesse estruturam o campo; campo: atores em interação, conflito e competição por tipos de capital (de poder); diversidade - os diversos campos são organizados e transformados em decorrência do processo de lutas por tipos de capital; o campo é definido pela relação de forças entre os atores e pelos tipos de capital em disputa; possibilidade de taxa de conversão, de alteração dos tipos de poder que estruturam o campo; o campo está em relação com o espaço social, que é um campo de forças (estrutura) e de lutas, dos atores 
sociais, pela sua reprodução ou transformação; processo permanente de produção social/acumulação/transformação/reprodução; reprodução ou transformação das estruturas; articulação dialética entre objetivismo e subjetivismo; construcionismo estruturalista ou estruturalismo construcionista.

Dessa forma, o entendimento da unidade de estudo como um campo, pode ampliar as perspectivas de análise, ao considerar a realidade como uma construção social, consolidada a partir da gênese social dos esquemas de percepção dos agentes e da estrutura, considerando esse espaço como um espaço plural onde coexistem diferentes agentes com diferentes capitais e interesses, o que pode acarretar situações de conflitos e disputas em detrimento da harmonia.

Nesse sentido, um olhar das redes interorganizacionais, envolvendo uma pluralidade de agentes, pode contribuir para o entendimento da lógica da prática dos agentes sociais num espaço social desigual e conflituoso, e de como os mecanismos de governança, a partir dessa complexidade, podem emergir.

\section{Proposição das redes organizacionais como um campo social}

É importante tratar a realidade das organizações, que se inserem em sistemas de relações de troca, como um fenômeno social disposto a funcionar de acordo com as instituições erigidas socialmente, sobre as quais repousam o sistema de crenças que inaugura e mantém a ordem da propriedade privada e a regulação dos diversos agentes sociais.

Por se tratar de um fenômeno, cada conjunto de organizações - ou campos organizacionais construídos nas diversas formas de rede existentes - terá também seu próprio sistema de relações, "governadas" pelo intricado sistema simbólico, e pelas estruturas objetivas que compõem um e outro campo organizacional, sem, contudo, abandonar as interferências do contexto social mais amplo e as propriedades interferentes de outros campos, na vida dos agentes daquele conjunto.

\section{0 problema da ação}

O esforço de tratar as organizações relacionadas como se fossem agentes sociais deve incorporar toda a complexidade de cada organização particularizada. O jogo que se joga dentro da organização é o mesmo jogo disputado entre as organizações. A diferença entre essas lutas está no seu nível de análise. Quem joga o jogo? Quais são os jogadores, senão os proprietários, os gerentes e demais membros que, de alguma forma, constituem os elos de ligação entre as organizações?

Quando se fala em ação organizacional, está se falando da ação dos agentes, e não do ser inanimado que é a própria organização. É uma ilusão acadêmica, e especialmente utilitarista, crer que as organizações fazem alguma coisa. Portanto, um primeiro ponto para se tratar das redes como campo social consiste em abandonar esse utilitarismo, como quer Bourdieu (1996, 1998, 2000 e 2003).

Nesse sentido, a ação dos agentes nas organizações em rede é entendida freqüentemente como uma ação pautada no cálculo consciente. É relativamente comum a transformação do trajeto percorrido pelos agentes, ao constituírem e transformarem uma rede organizacional, pelo projeto, reduzindo a ação desses agentes a uma consciência calculista. Fazer oposição a esse utilitarismo não é repudiar a racionalidade instrumental (no sentido weberiano) e utilitarista (no sentido do economismo comum ao mito das organizações burocráticas; é, na verdade, aceitar que a ação dos agentes não se resume a ela.

O habitus do sentido do jogo traz para o agente o jogo na pele (illusio). É esse habitus que, a partir da incorporação das estruturas imanentes de um campo, estrutura tanto a percepção do mundo como a ação nesse mundo. $\mathrm{O}$ acordo entre as estruturas incorporadas e as estruturas objetivas produz aquela experiência dóxica, na qual tudo parece dado. Isto posto, em oposição ao cálculo consciente, muito raramente as "estratégias" dos agentes sociais se apoiam numa verdadeira intenção estratégica. 
Assim, o interesse (em oposição ao desinteresse) dos agentes não é tanto aquilo que é intencionado, quanto pode ser participar, admitir que o jogo merece ser jogado; é não questionar se o jogo vale ou não a pena ser jogado. Ao mesmo tempo, algo que parece recorrente na interpretação de muitos pesquisadores que se ocupam das organizações em rede é a idéia de que os agentes sociais não têm interesses pessoais e estão dispostos a sacrificar seus interesses em função daquilo que é comum às organizações da rede, para o equilíbrio do que está em ordem. Essas idéias repercutem na visão harmônica, muito comum, nos trabalhos científicos dessa área. É como se os agentes do campo das organizações em rede fossem indiferentes uns aos outros. Dito de outra forma, para ter êxito dentro do campo das organizações em rede, os agentes precisam demonstrar a ação desinteressada com relação às posições dos demais agentes. Todavia, não existe indiferença entre os agentes quando estão em jogo os diferentes tipos de capital.

As interferências de outros campos (por exemplo, o campo econômico) são facilmente constatadas, principalmente, nas redes de organizações industriais, cuja origem se encontra em algum ponto da própria formação do campo econômico. Mas, as leis de funcionamento desse campo (negócios são negócios) não valem para todos os outros campos e muito menos para todos os tipos de redes. É o processo de diferenciação progressiva que marca a constituição do mundo social, o que leva aos nomos independentes dos de outros universos. O que dirige os agentes do campo científico a correr e concorrer não é a mesma condição que dirige os agentes do campo econômico, por exemplo. Diferentes conjuntos de organizações em rede têm (por serem diferentes) leis que não se resumem às leis do campo econômico. Os interesses dos agentes nesses diferentes conjuntos, nos diferentes campos de organizações em rede, não se limitam ao interesse lucrativo que o economismo insiste em reproduzir para todos os lugares específicos do campo social mais amplo.

Portanto, como campos sociais, as redes organizacionais não são espaços totalmente autônomos em relação aos demais campos, como, por exemplo, os campos econômico, político, científico, burocrático e ainda outros campos de organizações em rede, e nem tampouco apresentam fronteiras bem delimitadas. O funcionamento do campo é influenciado também por variáveis externas que nem sempre são controláveis e previsíveis, dificultando o processo de coordenação objetiva. O entendimento da ação coletiva como decorrente das disposições incorporadas pelos diversos grupos de agentes e organizações evidencia as diferenças ontológicas existentes entre as diversas organizações e, ainda, entre as diversas redes organizacionais. Ao mesmo tempo, permite compreender o ajustamento da estrutura às condições macro e microssociais.

\section{Da constituição e funcionamento}

Os diferentes tipos de capitais e a noção do volume e da estrutura destes, em campos específicos, permitem atribuir singularidades às formas organizacionais. Em cada tipo de arranjo poderão ser conferidos diferentes significados aos diferentes tipos de capitais, assim como provavelmente serão desenvolvidos diferenciados interesses socialmente constituídos (libidos sociais). A conjunção de organizações em rede incorre, formal e informalmente, na constituição de um "quase-Estado" (em uma analogia com o Estado em Bourdieu), responsável pela "regulamentação" das relações entre os agentes. Dentro da estrutura do campo surgem agentes e instâncias reguladoras cujas decisões políticas, econômicas e sociais fixam e/ou modificam as regras do jogo, explicitando a constituição do campo de poder.

A estrutura do campo organizacional, num dado momento da história, mostra a relação de força entre as organizações, que decorre das propriedades relacionais e disposicionais desse campo. Por exemplo, o estabelecimento dos contratos, que pretende garantir uma "eqüidade" e minorar o oportunismo, também pretende garantir, pelo menos, a forma de inserção dos agentes no campo e as posições objetivas dos agentes no campo das organizações em rede, ainda que os contratos reflitam e mascarem as relações posicionais entre as organizações dispostas em um conjunto articulado.

A constituição de um campo de organizações em rede é também a constituição de um "quase-Estado", que marca a historicidade desse campo. As formas de governança estrutural representam o "quase-Estado", detentor da capacidade de distribuição dos diferentes tipos de capital, por meio de sua pretensa institucionalização. O 
"quase-Estado" regulamenta as relações, aplica medidas repressivas às ações desviantes e é o objeto de disputa entre os agentes do campo das organizações em rede.

O "quase-Estado", inaugurado pela ação conjunta, é também "quase-autônomo". Ele é fruto dos investimentos dos diversos agentes, interfere na distribuição dos capitais dentro do campo e, conseqüentemente, intervém nas disposições dos agentes, tornando-se "quase-autônomo" ao longo dos anos. Ele é "quase-autônomo" porque é sempre objeto de disputa e mecanismo de exercício de poder simbólico.

Assim, as posições das organizações no campo serão decorrentes da posse e domínio de determinados tipos de capitais. A habilidade de uso desse excesso de capital pode transformar-se em capital simbólico, configurandose em condição favorável no campo, podendo ainda ser indutor de legitimação e dominação entre as demais entidades constituintes do espaço; considerando o "quase-estado" também um "quase-banco de capital simbólico".

As organizações em condições favoráveis, a partir de suas disposições subjetivas (ou seja, de seus habitus) tentarão impor sua visão de mundo (doxa) e irão estabelecer as regras do jogo (nomos), universalizando seus pressupostos dentro do campo de organizações em rede e a conseqüente probabilidade de ganhos; ou seja, irão instituir a distribuição dos custos e benefícios entre as organizações envolvidas, desde que consigam dominar o "quase-Estado". Dominar o "quase-Estado" é dominar o funcionamento do campo e de todos que entram nele; é deter os depositários dos diversos capitais que estão em jogo no campo. Dominar o "quase-Estado" é também objetivar e legitimar a incorporação de certas "práticas gerenciais", as quais representam os interesses daqueles que dominam o campo, ou daqueles que se valem dos seus diferentes capitais acumulados para estabelecer "as coisas certas a serem feitas" pelos membros participantes do conjunto.

Pela lógica de funcionamento do campo, o conflito pode emergir porque as organizações em posição de vantagem irão desenvolver "estratégias", interessadas em acumular e conservar os seus capitais. Quanto às organizações em situação contrária, estas procurarão modificar as regras do jogo, por meio da subversão do domínio do "quase-"Estado", tirando a legitimidade das bases sobre as quais os dominantes estão assentados.

As lutas podem tomar forma de negociação e de embates políticos. Na medida em que a distribuição dos tipos de capitais representa a própria historicidade do campo das organizações em rede, a conjugação de interesses entre as organizações (entendidas nesse momento como agentes) constitui um meio de produzir maior volume de capital e, conjuntamente, ocupar posições mais privilegiadas dentro do campo, além de ter melhores condições de influenciar a estruturação do próprio campo. A articulação política entre as organizações relacionadas é um movimento dinâmico que termina reproduzindo a lógica intrínseca de qualquer campo; qual seja, a de que vale a pena jogar o jogo.

\section{Considerações finais}

O recorte analítico das redes organizacionais, a partir de um enfoque político, utilizando algumas concepções de Bourdieu, pode oferecer leituras alternativas às visões românticas baseadas na máxima da cooperação e da confiança como forças motrizes e condições suficientes para a explicação e funcionamento dos arranjos entre as organizações. Ele também insinua a ampliação da noção de governança para além dos aspectos estruturais e objetivos, ao destacar as intricadas relações entre a objetividade e a subjetividade.

Com efeito, as interações passam a ser vistas como um jogo político estabelecido entre as diversas organizações, destacando a pluralidade de agentes envolvidos com seus diferentes tipos de capitais, interesses e o aparente desinteresse. O campo das redes organizacionais é, então, o espaço onde se manifestam as assimetrias de poder e também as lutas entre agentes com "estratégias" não necessariamente utilitaristas. 
A utilização dessa abordagem pode ainda ajudar a entender a pluralidade da natureza, tamanho e formas dos arranjos, enfatizando a lógica manifesta nas particularidades de cada história coletiva e não a prescrição de regras gerais de funcionamento das redes.

A temática mostra-se muito mais complexa do que previam as perspectivas harmoniosas. Permite ampliar as discussões inserindo uma condição histórica e dinâmica das relações interorganizacionais. Permite, ainda, suscitar críticas e insights sem a intenção de esgotar o assunto e nem tampouco reduzir a sociologia de Pierre Bourdieu à explanação de alguns conceitos. Destaca-se, entretanto, que a perspectiva proposta para a leitura das redes consiste em um campo fértil para pesquisas mais aprofundadas, sinalizando a possibilidade de estudos organizacionais. 


\section{Referências bibliográficas}

ALEXANDER, E. R. A structuration theory of interorganizational coordination: cases in environmental management. The International Journal of Organizational Analysis, v.6, n.4, 1996.

ALVAREZ, J. L.; SVEJENOVA, S. Governing network evolution in the quest for identity. Research paper. lese University of Navarra. n.435. Disponível em: <http://netec.mcc.ac.uk/WoPEc/data/Papers/ebgiesewpd-0435.html>. Acessado em: 15 nov. 2003.

ANDRADE, J. A. Actor-network: uma tradução para compreender o relacional e o estrutural nas redes interorganizacionais? In: ENCONTRO ANUAL DA ASSOCIAÇÃO NACIONAL DOS PROGRAM AS DE PÓS-GRADUAÇÃO EM ADM INISTRAÇÃO, 27., 2003, Atibaia. Anais... São Paulo: Anpad, 2003.

BENASSI, M. Governance factors in a network process approach. Scandinavian Journal of Management, v.11, n.3, 1995.

BONNEWITZ, P. Primeiras lições sobre sociologia de Pierre Bourdieu. Petrópolis: Vozes, 2003.

BORZEL, T. A. Organizing Babylon - on the different conceptions of policy networks. Public Administration, v.76, 1998.

BOURDIEU, Pierre. Razões práticas: sobre a teoria da ação. Campinas: Papirus, 1996.

O poder simbólico. Rio de J aneiro: Bertrand Brasil, 1998.

0 campo econômico. Campinas: Papirus, 2000.

A economia das trocas simbólicas. São Paulo: Perspectiva, 2003.

CALTON, J., M.; LAD, L. J. Social contracting as a trust-building process of network governance. Business Ethics Quarterly, v.5, n.2, 1995.

CASTELLS, M. A sociedade em rede. Rio de Janeiro: Paz e Terra, 1999.

CHILD, J.; RODRIGUES, S. B. Corporate governance and new organizational forms: the problem of double and multiple agency. In: ENCONTRO ANUAL DA ASSOCIAÇÃO NACIONAL DOS PROGRAM AS DE PÓS- GRADUAÇÃO EM ADM INISTRAÇÃO, 26., 2002, Salvador. Anais... Rio de Janeiro: Anpad, 2002.

CLEGG, S. R.; HARDY, C. Introdução: organização e estudos organizacionais. In: CLEGG, S. R.; HARDY, C.; NORD, W. Handbook de Estudos Organizacionais. São Paulo: Atlas, 1999. p.27-57.

ENDE, J. V. D. Modes of governance of new service development for mobile networks. A life cycle perspective. Research Policy, n.32, 2003.

GRANOVERTTER, M. Economic action and social structure. American Journal of Sociology, v.91, n.3, 1985.

. Economic institutions as social constructions: a framework for analysis. Acta Sociologia, v.35. n.3, 1992.

GULAT, R. Where do interorganizational networks come from? American Journal of Sociology, v.104, n.5, 1999.

JONES, C.; HESTERLY, W. S.; BORGATTI, S. P. A general theory of network governance: exchange conditions and social mechanisms. Academy of Management Journal, 1997.

KLIJN, E.; KOPPENJAN, J. F. M. Public management and policy networks: foundations of a network governance. Public Management, v.2, 2000.

LEÃO, F. P. S. J. Formação e estruturação de campos organizacionais: um modelo para análise do campo cultural. In: ENCONTRO ANUAL DA ASSOCIAÇÃO NACIONAL DOS PROGRAMAS DE PÓS-GRADUAÇÃO EM ADM INISTRAÇÃO, 25., 2001, Campinas. Anais... Campinas: Anpad, 2001.

Formação e estruturação do campo organizacional dos museus da Região Metropolitana do Recife. In: ENCONTRO ANUAL DA ĀSSOCOCIAÇÃO NACIONAL DOS PROGRAMAS DE PÓS- GRADUAÇÃO EM ADMINISTRAÇÃO, 26., 2002, Salvador. Anais... Rio de Janeiro: Anpad, 2002.

MISOCZKY, M. C. A. Campo de poder e ação em Bourdieu: implicações de seu uso em estudos organizacionais. In: ENCONTRO ANUAL DA ASSOCIAÇÃO NACIONAL DOS PROGRAMAS DE PÓS- GRADUAÇÃO EM ADM INISTRAÇÃO, 25., 2001, Campinas. Anais... Campinas: Anpad, 2001.

NOHRIA, N. Is a network perspective a useful way of studying organizations? In: NOHRIA, N.; ECCLES, R. G.(Ed.). Networks and organizations: structure, form and action. Boston: Harvard Business School Press, 1992. p.1-22.

PECI, A. Emergência e proliferação de redes organizacionais - marcando mudanças no mundo dos negócios. In: ENCONTRA ANUAL DA ASSOCIAÇÃO NACIONAL DOS PROGRAMAS DE PÓS- GRADUAÇÃO EM ADM INISTRAÇÃO, Foz do Iguaçu. Anais... Rio de Janeiro: Anpad, 2000.

PINTO, L. Pierre Bourdieu e a teoria do mundo social. Rio de janeiro: Editora FGV, 2000. 
POWELL, W. Neither market nor hierarchy: networks forms of organization. Neither market nor hierarchy: networks form of organizations. Research in Organizational Behavior, v.12, 1990.

SAUVÉE, L Efficiency, effectiveness and the design of network governance. In : 5th CONFERENCE OF CHAIN AND NETWORK MANAGEMENT IN AGRIBUSINESS AND THE FOOD INDUSTRY, Noordwijk an Zee, Países Baixos, 7-8 juin 2002. Disponível em: <http://www.rch2.sia.ucl.ac.be:82/rch2/uniface2.cgi/RCH_liste_unitel.ch1?ECRU-44k>. Acessado em: 15 nov. 2003.

. Allocation of decision rights within networks: configuration and definition principles. In:19th IMP CONFERENCE UNIVERSITY OF LU'GĀNO, Lugano, Suíça, Sep. 2003. Disponível em: <http//www.impgroup.org/uploads/papers/4414.pdf>. Acessado em: 15 de novembro de 2003.

SUZIGAN, W., GARCIA, R., FURTADO, J. Governança de Sistemas de MPMEs em Clusters Industriais. Texto apresentado no Seminário Internacional - Políticas para Sistemas Produtivos Locais de MPMEs. Rio de Janeiro, 11-13 de março de 2002. Disponível em: $<$ <ttp://www.prd.usp.br/redecoop/papers.html>. Acessado em : 10 de outubro de 2003.

WILLIANSON, O. E. Markets and Hierarchies: analysis and anti trust implications. New York: Macmillan, 1975

WILSON, S; GARCIA, R.; FURTADO, J. Governança de sistemas de MPME em cluster industriais. In: Proposição de políticas para a promoção de sistemas produtivos locais de micro, pequenas e médias empresas. Disponível em: <http://www.ie.ufrj.br/>. Acessado em: 15 nov. de 2003.

VIEIRA, M. M. F.; CARVALHO, C. A. P.; LOPES, F. D. The Structuring of the Organizational Field of Theatres and Museums in the South of Brazil. IN: XVII Egos Colloquium, Lyon - France. European Group for Organizational Studies. 2001 